\title{
Steady State and Transient Thermal Analysis of Switched Reluctance Machine
}

\author{
E. Annie Elisabeth Jebaseeli and S. Paramasivam
}

\begin{abstract}
This paper presents the two dimensional (2-D) steady state and transient thermal analysis in Switched Reluctance machine (SRM) to observe actual heat distribution in the parts of the machine using finite element method. Electromagnetic losses which form the heat source is calculated taking into consideration both skin effect and proximity effect. A 2-D steady state analysis is carried out to observe the temperature distribution and maximum temperature for wide range of speed and load conditions. From the analysis it is found that the maximum temperature is reached in the speed range of $1500 \mathrm{rpm}$. The load corresponding to maximum temperature is taken as initial condition for the transient thermal analysis. From the transient analysis, heat distribution at various load steps and the time to reach the steady state are observed. Simulation results for a 6/4 SRM are presented under steady state and transient conditions. As a result, thermal analysis plays a great significance for the long term stability of the machine.
\end{abstract}

Index Terms-Core loss, copper loss, finite element analysis, switched reluctance machine, thermal analysis.

\section{INTRODUCTION}

With the increasing pressure on the design of energy saving electrical machines, a new trend has come to carry out thermal analysis along with the traditional Electromagnetic field analysis. The Electric currents and friction in an electric machine generate heat. Hence temperature of different parts of the machine rise which could cause deterioration of insulation in windings [1], thermal stress, efficiency reduction and this may lead to motor failure. Also under high loads, temperature rise influences the machine electrical and magnetic parameters [2]. It is therefore necessary to maintain the temperature of the machine components within permissible limits for safety operation [3]. So the temperature rise analysis of Switched reluctance machine is implemented in this paper.

For accurate calculations, the effect of electromagnetic losses and the heat transfer mechanisms are discussed. Heat transfer coefficients are calculated based on two conditions such as iron-outside air and iron- inside air convection. This paper in its Section II deals with electromagnetic losses estimation and the thermal analysis of Switched reluctance machine. The simulation results under steady state and transient conditions are presented in section III for a 6/4 SRM whose specifications are given in Table I. Section IV includes the conclusive remarks.

Manuscript received September 13, 2012; revised October 24, 2012.

E. Annie Elisabeth Jebaseeli is from Sathyabama University, Chennai, India (e-mail: annjeba@yahoo.co.in).

\section{Thermal ANAlysis of SWITCHED RELUCTANCE MACHINE}

Submit your manuscript electronically for Modern thermal analysis can be classified into three methods [4] namely

1) Experimental method

2) Lumped parameter thermal model method

3) Numerical analysis method

Experimental method is suitable for already designed and fabricated machine to decide the precise cooling strategy based on its thermal behavior. But accuracy is less in the case of complex geometrical machine structures and the non-linear characteristics of the materials.

In Lumped thermal model method, thermal problem is solved using thermal networks analogous to electrical circuits. It involves many assumptions and a simplified form of empirical formula. The result shows only the overall distribution of the temperature of the motor but does not show the point of internal temperature [5].

To design energy-saving Electrical machines, numerical analysis is one of the most promising technologies. Most commercially available numerical analysis computer programs use finite element method. No assumptions are made regarding flux path or related empirical factors. A field solution can be obtained even with time-variable fields and with materials that are non-homogeneous, anisotropic or non linear.

\section{A. Heat Source}

The two main components of electromagnetic losses in Switched reluctance Machine are core losses in the laminations and copper losses in the windings. These losses are the heat source in a thermal analysis [6].

For any motor the copper losses can be calculated from the $I^{2} R$ products, where $R$ is the effective resistance of one phase winding. Due to Skin and proximity effects, the value of $\mathrm{R}$ is greater than the DC resistance. When an electromagnetic wave interacts with a conductive material, mobile charges within the material oscillates with the frequency similar to the impinging fields. This constitutes an alternating electric current, the magnitude of which is greatest at the conductor surface. The decline in current density with depth is known as the skin effect and the skin depth is a measure of the distance over which the current falls to 1/e of its original value.

The value of eddy currents in a separated conductor depends on the proximity of the conductor to the steel core. In addition, the magnetic field created by any single conductor influences other conductors which are called proximity effect. Considering the above, the expression for the calculation of copper losses in the switched reluctance 
machine taking into account the fundamental and $n$ higher harmonic components of the phase current [7] is given by

$$
P_{c u}=\mathrm{Ns} \sum_{k=1}^{n} \vec{I}_{k}^{2} \boldsymbol{R}_{D C}\left[W_{s k}\left(\frac{d \cdot n_{w}}{\delta_{k}}\right)+\frac{4 n_{L}^{2}-1}{3} W_{p k}\left(\frac{d \cdot n_{u}}{\delta_{k}}\right)\right]
$$

where

$$
W_{s k}\left(\frac{d \cdot n_{w}}{\delta_{k}}\right)
$$
is the factor which accounts for the losses due to the skin effect,

$$
W_{p k}\left(\frac{d \cdot n_{w}}{\delta_{k}}\right)
$$
due to the proximity effect,

$$
\overrightarrow{I_{k}}=\sqrt{\frac{1}{T} \int_{0}^{T} i_{k}^{2} d t}
$$

harmonic current

$\delta_{k}$ is the skin depth in copper of the $k$-th harmonic current.

Core losses in switched reluctance machine are relatively low but in high speed applications they become the dominant component of the total losses. Prediction of core loss is difficult because the flux waveforms are non-sinusoidal and have different shapes with various frequencies for different parts of the magnetic circuit. Thus using a modified Steinmetz equation core loss can be calculated as

$$
p_{\mathrm{Fe}=} f_{\sin } c_{m} f_{e q}^{\alpha-1} \widehat{B}^{\beta}
$$

where $f_{\text {sin }}=\frac{1}{T}, c_{m}, \alpha, \beta$ are the coefficients used in the conventional Steinmetz equation .Based on the above expressions losses are calculated from [8] and listed in Table I.

TABLE I: RESULtS OBTAINED FROM THE SIMULATION FOR THE CORE AND COPPER LOSSES

\begin{tabular}{|l|c|c|c|c|c|}
\hline $\begin{array}{l}\text { Rotational } \\
\text { speed (rpm) }\end{array}$ & 500 & 1000 & 1500 & 2000 & 2500 \\
\hline $\begin{array}{l}\text { Average } \\
\text { current (amps) }\end{array}$ & 2.52 & 6.22 & 9.98 & 10.20 & 10.31 \\
\hline $\begin{array}{l}\text { Copper loss } \\
\text { (watts) }\end{array}$ & 37.54 & 57.15 & 57.67 & 36.71 & 23.86 \\
\hline $\begin{array}{l}\text { Core loss } \\
\text { (watts) }\end{array}$ & 9.19 & 18.376 & 27.56 & 36.752 & 45.94 \\
\hline
\end{tabular}

\section{B. Geometrical Model}

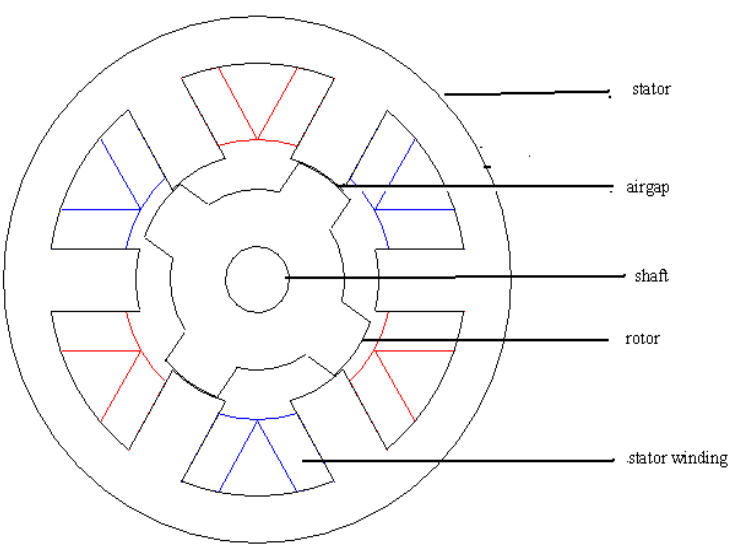

Fig. 1. Geometrical model of 6/4 SRM
A two dimensional (2-D) model is shown in Figure. 1. Whose specifications are given in Table II. The model consists of (a) stator of machine (b)stator windings(c) rotor (d)air and (e) shaft.

TABLE II: SPECIFICATIONS OF 6/4 SRM

\begin{tabular}{|l|l|}
\hline Number of stator phases & 6 \\
\hline Number of rotor phases & 4 \\
\hline Stator outer diameter(m) & 0.055 \\
\hline Rotor outer diameter(m) & 0.026 \\
\hline Shaft length(m) & 0.08522 \\
\hline Air gap length(m) & 0.00025 \\
\hline
\end{tabular}

Corresponding to the physical dimensions given in Table III and from the core and copper losses of the machine, quantity of heat generation $\mathrm{Q}$ is calculated for different parts like stator core and coils and are presented in Table IV. A finite element heat run [9] is simulated with the value of $\mathrm{Q}$ (watts $/ \mathrm{m}^{3}$ ) which is the main heat source.

TABLE III: PHYSICAL DIMENSIONS OF 6/4 SRM

\begin{tabular}{|l|c|}
\hline Area of the coil segment & 134 E-006 sq.m \\
\hline Total coil area & 1608 E-006 sq.m \\
\hline Shaft Length & $85.22 \mathrm{E}-003 \mathrm{~m}$ \\
\hline Volume of coil & 137033 E-009 cu.m \\
\hline Area of the stator & 4640 E-006 sq.m \\
\hline Volume of the stator & 395420 E-009 cu.m \\
\hline
\end{tabular}

TABLE IV: QUANTITY OF HEAT GENERATION

\begin{tabular}{|c|c|c|}
\hline Speed in rpm & $\begin{array}{c}\text { Heat generation in } \\
\text { coil }\left(\text { watts } / \mathrm{m}^{3}\right)\end{array}$ & $\begin{array}{c}\text { Heat generation in } \\
\text { core }\left(\mathrm{watt} / \mathrm{m}^{3}\right)\end{array}$ \\
\hline 500 & $2.7 \mathrm{E}-013$ & $1.18 \mathrm{E}-013$ \\
\hline 1000 & $4.17 \mathrm{E}-013$ & $1.91 \mathrm{E}-013$ \\
\hline 1500 & $4.21 \mathrm{E}-013$ & $2.15 \mathrm{E}-013$ \\
\hline 2000 & $2.68 \mathrm{E}-013$ & $2.2 \mathrm{E}-013$ \\
\hline 2500 & $1.71 \mathrm{E}-013$ & $2.4 \mathrm{E}-013$ \\
\hline
\end{tabular}

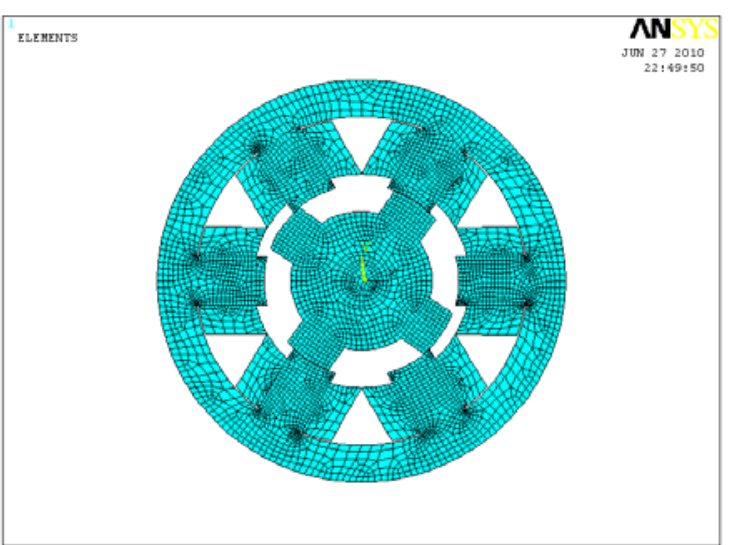

Fig. 2. 2-D Finite element model of SRM 
In finite Element Analysis, to increase the accuracy, a fine subdivision of the structure is carried out with finite elements of smaller dimension. In practice several types of elements are used depending upon the geometrical shape of the region under consideration. In two dimensional problems, the elements used are triangles, rectangles and quadrilaterals. In this method, loss analysis is carried out by finite element analysis and the results can be applied to the temperature analysis. Using these results as the heat source, the temperature rise is estimated. A 2-D Finite element model of SRM is shown in Fig. 2.

In this model, plane55 element is used for analysis. The model is meshed with two dimensional quadrilateral element and fine discretization is done at the expected high gradient area of the machine.

In the above model, the element has four nodes with a single degree of freedom and temperature at each node. The element is applicable to a 2-D steady state or transient thermal analysis. The element can also compensate for mass transport heat flow from a constant velocity field. If the model containing the temperature element is also to be analysed structurally, the element should be replaced by an equivalent structural element, which can be used for coupled field analysis also.

Thermal parameters listed in Table $\mathrm{V}$ are required for the prediction of the temperatures in the electrical machine [10].

\begin{tabular}{|c|c|c|}
\hline \multicolumn{3}{|c|}{ TABLE V: THERMAL PARAMETERS } \\
\hline Material & $\begin{array}{c}\text { Thermal Conductivity } \\
(\mathrm{w} / \mathrm{m} \text { K) }\end{array}$ & $\begin{array}{c}\text { Density } \\
(\mathrm{Kg} / \mathrm{m} 3)\end{array}$ \\
\hline Copper & 380 & 8940 \\
\hline Steel & 40 & 7850 \\
\hline Air & 0.024 & 1.165 \\
\hline
\end{tabular}

\section{Simulation Results AnAlysis}

\section{A. Steady State Thermal Analysis}

In steady state analysis, conductive heat transfer with various boundary conditions is obtained from the Fourier law as

$$
\frac{1}{r} \frac{\partial}{\partial r}\left(k r \frac{\partial T}{\partial r}\right)+\frac{1}{r^{2}} \frac{\partial}{\partial \theta}\left(k \frac{\partial T}{\partial \theta}\right)+\frac{\partial}{\partial Z}\left(k \frac{\partial T}{\partial Z}\right)+\dot{q}=0
$$

1) Heat transfer by convection

Liquid and gas particles near heated body become lighter and rise, giving way to cooler particles which in turn get heated and rise. Thus due to changes in fluid density, natural convection takes place. This takes place on the external housing of the machine. In modern machines heat is removed by forced convection. The usual method is by blasting air on heating surfaces.

In convection the rate at which heat is removed is governed by Newton's Law

$$
\frac{P}{A}=h\left(T_{1}-T_{2}\right)
$$

where $\left(T_{1}-T_{2}\right)$ is the temperature difference between the surface being cooled and the cooling medium. The value of convection heat transfer coefficient $h$ depends on viscosity, thermal conductivity, specific heat and other properties of the coolant. With the help of empirical expressions, an estimation of the coefficients is possible.

The set of dimensionless numbers used in the calculation of convection heat transfer coefficients are [11], [12].

Reynolds number

$$
\mathrm{Re}=\frac{\rho v L}{\mu}
$$

where

$$
\begin{aligned}
& \rho \text {-fluid density }\left(\mathrm{kg} \mathrm{m}^{-3}\right) \\
& \left.\mu \text {-fluid dynamic viscosity ( } \mathrm{kgs}^{-1} \mathrm{~m}^{-1}\right) \\
& \left.\nu \text { - fluid velocity ( } \mathrm{ms}^{-1}\right) \\
& \text { L- characteristic length of the surface(m) }
\end{aligned}
$$

Grashof number

$$
G r=\frac{\beta g \theta \rho^{2} L^{3}}{\mu^{2}}
$$

where $\beta$-coefficient of cubical expansion of fluid $\left({ }^{0} \mathrm{C}^{-1}\right)$ $\mathrm{g}$ - gravitational force of attraction $\left(\mathrm{ms}^{-2}\right)$

fluid $\left({ }^{0} \mathrm{C}\right)$

$\theta$ - temperature difference between surface and

Prandtl number

$$
\mathrm{P} \mathrm{r}=\frac{c \mu}{\lambda}
$$

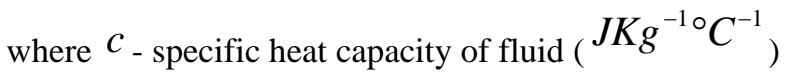

$$
\lambda \text { - thermal conductivity of fluid }\left(W m^{-1} \circ C^{-1}\right)
$$

Nusselt number

$$
N_{u}=\frac{h L}{\lambda}
$$

Nusselt number is often used for the calculation of the convection heat transfer coefficient $h\left(\mathrm{Wm}^{-2}{ }^{\circ} \mathrm{C}^{-1}\right)$

$$
h=\frac{\lambda N_{u}}{L}
$$

For natural convection the general form of convection correlation is

$$
N_{u}=a(G r \operatorname{Pr})^{b}
$$

For forced convection the general form of convection correlation is

$$
N_{u}=a\left(R_{e}\right)^{b}(\mathrm{Pr})^{c}
$$

where $\mathrm{a}, \mathrm{b}$ and $\mathrm{c}$ are constants. 
Gr. $\operatorname{Pr}=\mathrm{Ra}$ is the Rayleigh number.

In a forced convection system the value of Re judges if there is laminar or turbulent flow. It is identified by Gr. Pr product in natural convection system.

For laminar flow $\left(\operatorname{Re}<5 \mathrm{x}^{10^{5}}\right)$ and $(0.6<\operatorname{Pr}<50)$

For turbulent flow $\left(\operatorname{Re}>5 \times 10^{5}\right)$

If the fluid velocity is larger then turbulence is induced. In this case, heat transfer is increased due to efficient mixing of hot and cold air.

The ambient temperature was set as $30^{\circ} \mathrm{C}$ and a steady state analysis was carried out. From figure 3 , it is clear that at $1000 \mathrm{RPM}$ maximum temperature of $50.022^{\circ} \mathrm{C}$. occurs in the internal coil which is due to higher copper loss. At steady state, the temperature rise due to copper loss depends on the current passing through the coil and the convective coefficients. As load increases, say at 2000 RPM, core loss has higher value than the copper loss. Hence maximum temperature in the internal coil gets reduced to $43.702^{\circ} \mathrm{C}$ due to lesser amount of heat generation. Table VI is the summary of steady state thermal analysis performed on the machine. In the steady state analysis, the temperature increases and reaches the maximum temperature of $50.5^{\circ} \mathrm{C}$. at 1500 RPM .This region is considered as initial condition and Transient thermal analysis was carried out.

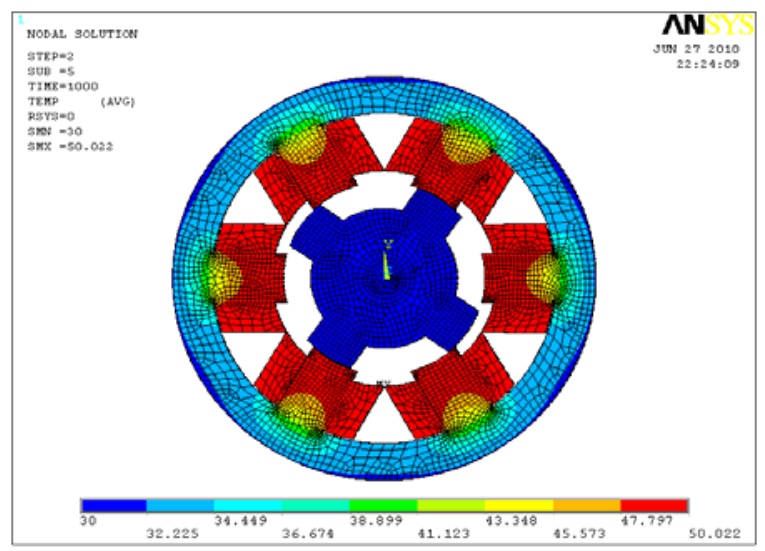

Fig. 3. Steady state temperature distribution at $1000 \mathrm{rpm}$

TABLE VI: RESULTS OF STEADy STATE THERMAL ANALYSIS FOR VARIOUS SPEED

\begin{tabular}{|c|c|}
\hline Speed (RPM) & Maximum Temperature $\left({ }^{\circ} \mathrm{C}\right)$ \\
\hline 500 & 43.66 \\
\hline 1000 & 50.022 \\
\hline 1500 & 50.494 \\
\hline 2000 & 43.702 \\
\hline 2500 & 39.922 \\
\hline
\end{tabular}

\section{B. Transient Thermal Analysis}

In Transient thermal analysis, temperature varies with respect to time [13].

In a hollow cylinder containing heat source, Conductive heat transfer with various boundary conditions is obtained from the Fourier law[14] in cylindrical coordinate as

$$
\frac{1}{r} \frac{\partial}{\partial r}\left(k \frac{\partial T}{\partial r}\right)+\frac{1}{r^{2}} \frac{\partial}{\partial \theta}\left(k \frac{\partial T}{\partial \theta}\right)+\frac{\partial}{\partial \mathcal{Z}}\left(k \frac{\partial T}{\partial \mathcal{Z}}\right)+\dot{q}=\rho c \frac{\partial T}{\partial t}
$$

where $\dot{q}$ is the heat source which is substituted by the losses. Frame, stator yoke and rotor core of Switched reluctance machine can be considered as hollow cylinders. Stator teeth and rotor teeth are considered as partial hollow cylinders with stator and rotor to be laminated. Also, the boundary conditions are conductive heat transfer from the body and the axial shaft at two ends.

Natural Convection is considered on stator external surface. Internal surfaces are subjected to have forced convection due to the rotation of the rotor.

The boundary conditions are at $t=0$, the machine has atmospheric temperature $t>0$, the temperature increases due to heat generation in the machine.

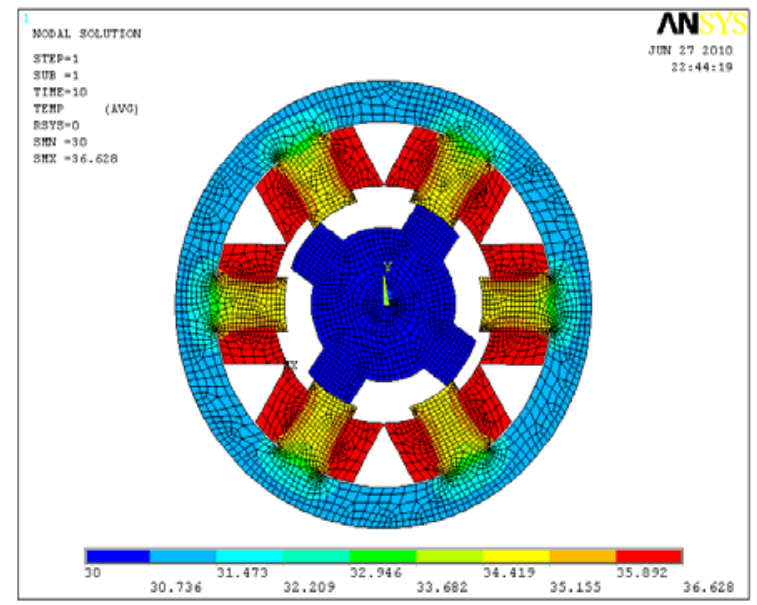

Fig. 4. Temperature distribution after 10 seconds

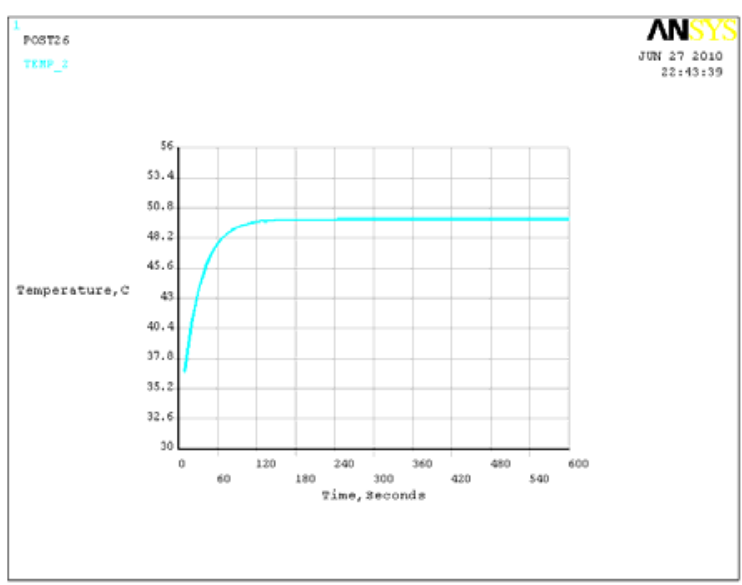

Fig. 5. Transient temperature-time curve

In the Transient thermal analysis, the time taken by the machine to reach steady state temperature can be found out. The results of simulation showing temperature variation from 0 to 1000 seconds is shown in the Table VII. It is observed that after 10 seconds the temperature has increased only in the coil wound on the stator and then gradually increases in the stator pole. Figures 4 and 5 represent the results of transient thermal analysis. It shows that steady temperature is reached after 120 seconds. Hence heat distribution within the components of the machine with respect to time can be analysed accurately with transient thermal analysis. 
TABLE VII: RESULTS OF TRANSIENT THERMAL ANALYSIS

\begin{tabular}{|c|c|}
\hline Time (seconds) & Maximum Temperature $\left({ }^{\circ} \mathrm{C}\right)$ \\
\hline 10 & 36.628 \\
\hline 20 & 40.765 \\
\hline 50 & 47.148 \\
\hline 110 & 49.498 \\
\hline 213 & 49.845 \\
\hline 513 & 49.855 \\
\hline 1000 & 50.449 \\
\hline
\end{tabular}

\section{CONCLUSION}

In electrical machines, the insulation life time varies inversely with the working temperature. Hence to improve the machine performance and its reliability, a thermal analysis is carried out by 2-D finite element analysis under steady state and transient conditions. It is observed that a maximum temperature of $50^{\circ} \mathrm{C}$ is obtained after 120 seconds. So, the machine has a temperature rise within the permissible limits. Based on this, the weight of the materials used and the number of prototypes built can be minimised.

\section{REFERENCES}

[1] S. Inamura, T. Sakai, and K. Sawa, "A Temperature Rise Analysis of Switched Reluctance Motor Due to the Core and Copper Loss by FEM,” IEEE Trans. Magn, vol. 39, no. 3, pp. 1554-1557, May 2003

[2] Balamurugan and P. Sumathi, "Analysis of Temperature Rise in Switched Reluctance Motor Due to the Core and Copper Loss by Coupled Field Finite Element analysis," International conference on Power System Technology, pp. 630-634, November 2004.

[3] D. S. B. Fonseca, C. M. P. Cabrita, and M. R. A. Calado, “Thermal Modelling and characterization of Electrical achines and calculation of current ratings," Fourth IET conference on power electronics, Machines and Drives, pp. 475-479, April 2006

[4] K. Vijayakumar, R. Karthikeyan, S. Paramasivam, R. Arumugam, and K. N. Srinivas, "Switched Reluctance Motor Modeling, Design, Simulation ,and Analysis: A Comprehensive Review," IEEE Trans. Magn, vol. 44, no. 12, pp. 4605-4616, December 2008.

[5] H. Sun, J. Gao, Y. Dong, and Yi Zheng, "Analysis of Temperature Field in Switched Reluctance Motor Based on Finite- element," 11th international conference on Electrical Machines and systems, pp. 597-601, Oct. 2008.

[6] J. Faiz, B. Ganji, C. E. Carstensen, K. A. Kasper, and R. W. D. Doncker, "Temperature Rise Analysis of Switched Reluctance Motors Due to Electromagnetic Losses," IEEE Trans. Magn, vol. 45, no. 7, July 2009.

[7] A. Matveev, "Development of Methods, Algorithms and Software for optimal design of Switched reluctance drives," Doctoral Thesis, Eindhoven Technische Universiteit, Eindhoven, 2006.

[8] P. O. Rasmussen, Switched Reluctance Design and Simulation-Thesis version.

[9] K. N. Srinivas and R. Arumugam, "Thermal Characterization Through Finite Element Analysis of the Switched Reluctance Motor," IEEE Region 10 International conference on Electrical and Electronics technology, pp. 819-823, vol. 2, 2001.

[10] W. Wu, J. B. Dunlop, S. J. Collocott, and B. A. Kalan, "Design optimization of a Switched Reluctance Motor by Electromagnetic and Thermal Finite-Element Analysis," IEEE Trans. Magn, vol. 39, no. 5, pp. 3334-3336, September 2003.

[11] D. A. Staton and A. Cavagnino "Convection Heat transfer and Flow Calculations Suitable for Electrical Machines Thermal Models," IEEE trans. Industrial Electronics, vol. 55, no. 10, 2008.

[12] D. A. Staton and A. Cavagnino, "Convection Heat transfer and Flow Calculations Suitable for Analytical Modelling of Electrical Machines," IEEE Annual conference on Industrial Electronics, pp. 4841-4846, Nov 2006.

[13] K. N. Srinivas and R. Arumugam, "Analysis and Characterization of Switched Reluctance Motor: Part II- Flow, Thermal, and Vibration Analyses," IEEE Trans. Magn, vol. 41, no. 4, April 2005.

[14] H. Rouhani, J. Faiz, and C. Lucas, "Lumped thermal model for Switched Reluctance Motor applied to mechanical design optimization,” J. Mathematical and computer modelling, pp. 625-638, 2007.

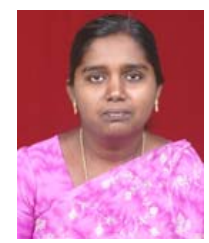

Machines.

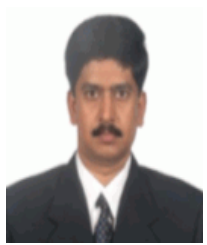

E. Annie Elisabeth Jebaseeli received her B.E degree in Electrical and Electronics Engineering from Madurai Kamaraj University, Tamilnadu, India in 1993 and M.E degree from Sathyabama University, Tamilnadu, India in 2004. In 1998 she joined in the department of Electrical and Electronics Engineering and working as a Assistant professor in Sathyabama University, India. Her Research interest is modeling of Electrical

S. Paramasivam received his BE from GCT, Coimbatore, in 1995 and ME from PSG College of Technology, Coimbatore in 1999 and his Ph.D in Electrical Engineering from Anna University, Chennai, India. He is the Assistant General Manager, ESAB Engineering Services Pvt. Ltd., Chennai, India. His research interest include power Electronics, special machines analysis, drives and control. 